\title{
Climate change and vine protection : the case of mildews management in Burgundy
}

\author{
S. Zito ${ }^{1}$, A. Caffarra ${ }^{2}$, Y. Richard ${ }^{1}$, T. Castel $^{1}$, B. Bois ${ }^{1,3}$ \\ ${ }^{1} C R C$ - UMR Biogeosciences, Université Bourgogne Franche Comté / CNRS, 6 Bd Gabriel, 21000 Dijon, France \\ ${ }^{2}$ ITK, Avenue de l'Europe, 34830 Clapiers \\ ${ }^{3}$ Institut Universitaire de la Vigne et du Vin, Université Bourgogne Franche Comté, rue Claude Ladrey, 21000 Dijon,
}

France

\begin{abstract}
Viticulture worldwide is currently facing two major challenges: adapting to climate change and reducing its environmental footprint. Plant protection is a central aspect of these challenges, firstly because pests and diseases development is strongly controlled by climate conditions, and secondly, because viticulture requires in many regions large quantities of pesticides. Phytosanitary protection is even more crucial for terroir-based viticulture areas, because the negative image given by excessive pesticide use impacts the whole region which reputation is partly built on environmental friendly practices. Moreover, most of terroir wines sensory properties and fame rely on specific cultivars, which makes it difficult to replace them using diseases resistant varieties. This study addresses the potential impact of climate change on pesticide use to control powdery and downy mildew in Burgundy. To assess the past evolution of diseases risk, a database composed by yearly number of applications of phytosanitary treatments for powdery and downy mildew diseases was built. This information was collected from 400 grapevine growers originating from 5 sub-regions of Burgundy. The data refer to yearly average number of treatments during the 1995-2014 period. Pesticide applications was related to climate by means of multiple linear regression models between the average number of treatments for powdery and downy mildews control and monthly temperature and monthly rainfall indices from April to July. Models providing the lowest error (estimated trough leave-one-out cross-validation) were selected for each of the 5 Burgundy wine sub-regions. According to each region, mildews yearly treatments number were significantly related to monthly climate data. In most models, May and June average temperature were selected with negative regression coefficients while April and May monthly precipitation were selected with positive regression coefficients. These models were fed with 1980-2100 temperature and rainfall projected data using CMIP5 RCP8.5 scenario from 18 GCM (General Circulation Models) statistically downscaled and debiased to match a daily $12 \mathrm{~km}$ target resolution. Increasing temperature and a slight ensemble rainfall increase (depending on the GCM) simulated during spring and early summer had inverse effects on models trend. However, regression models project a decreasing trend of the number of treatments for mildews control along the $21^{\text {st }}$ century, based upon GCM data. Spraying numbers are expected to slightly vary in the future $(-4,8$ to $-34.1 \%$ reduction), which strengthens the need for alternative plant protection strategies to match both consumer and policies promoting lower pesticides use for viticulture.
\end{abstract}

Keywords: downy mildew, powdery mildew, grapevine, climate change, Burgundy, pesticides

\section{Introduction}

Ever since the beginnings of viticulture, insects and diseases have caused significant yield and quality losses, their management often leading to pollution [1], human health deterioration [2] and economic consequences [3]. Climate change impacts on grapevine and parasites biology and their populations are obvious, therefore, plant protection is expected to evolve.

Surprisingly few researches have focused phytosanitary risks observed and projected (21 $1^{\text {st }}$ century) evolution in viticulture. Some studies based their research on empirical models in order to simulate downy mildew expected earliness and severity based on spraying observations [4,5] while others used mechanistic modelling to simulate host vs pest/pathogen interaction for European grapevine moth (Lobesia botrana), powdery mildew [6] and downy mildew [7]. All these study were based on projected data derived from one or two atmosphere-ocean general circulation models (AOGCM). It is highly to water related climate variables. It is highly recommended to use an ensemble approach to assess climate impacts. Yet, the epidemiology of grapevine major diseases (i.e. mildews according to [8] survey) strongly depends on water (rainfall, leaf wetness duration and air relative humidity), and when not related to temperature only, climate projections strongly vary according to the GCM parametrization $[9,10]$. There is consequently a need to evaluate the sensitivity of phytosanitary risks assessment simulations in response to a large number of climate projections, to better assess the possible evolution of grapevine protection in the future. Our study aims at documenting the evolution of powdery and downy mildew risks in relation with climate change, from 1980 to 2100, using 18 downscaled/debiased GCM data. This research (i) assesses mildews "pressure" over the past 20 years for the Burgundy wine region, as shown in figure 1; (ii) builts regression-based empirical models to relate the number of treatments per year necessary to control the diseases and monthly climate variables (iii) projects the number of treatments throughout the $21^{\text {st }}$ century using statistically downscaled CMIP5 (Coupled Model Intercomparison Project [11]) climate projection (scenario RCP8.5). 


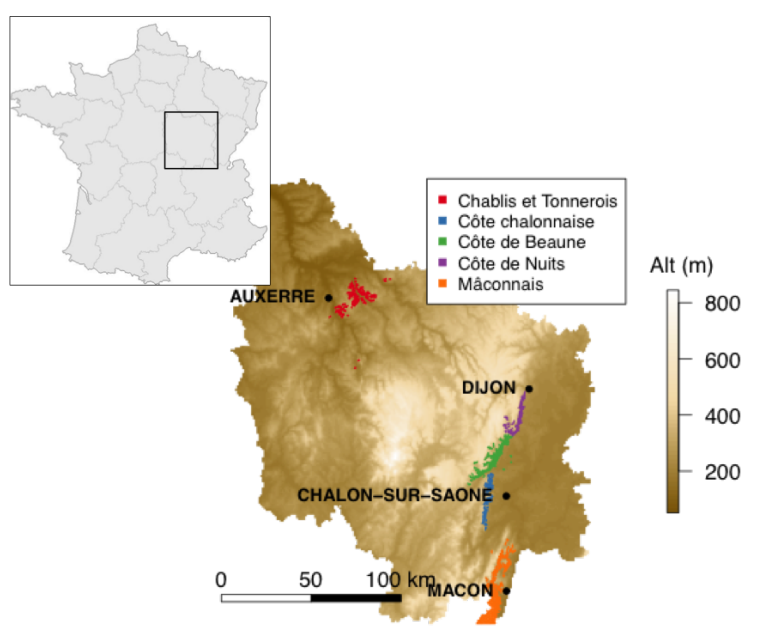

Figure 1. The studied area including the 5 wine sub regions of Burgundy France.

\section{Material and methods}

\subsection{Spraying mildew database}

Disease pressure is a fuzzy concept used by various grape growing stakeholders which assessment metrics are yet to be developed. Disease pressure can be roughly estimated by using different indicators such as the number of applied treatments, experts (e.g. consultants) or grapegrowers opinions, and disease intensity levels observed in the vineyard.

In this study, we used the number of applications done by grapegrowers each year as a bulk estimate of the disease intensity, as previously performed by [4]. We collected this information from 400 grapevine growers originating from all 5 sub regions of Burgundy. In this paper, we focus on the data of the "Côte de Beaune" collected by the Agricultural Regional Chamber of Burgundy which refer to yearly average number of powdery and downy mildew treatments during the 19952014 period. The number of winegrowers varies between 38 and 135 depending on year. We refer hereafter to « mildews pressure » when addressing the average number of treatment made each year for both powdery and downy mildew diseases.

\subsection{Climate database}

\subsubsection{Observation}

Monthly climate data was obtained for each pixel of a 12 $\mathrm{km}$ resolution grid elaborated though interpolation of daily climate data from Meteo France weather stations. Interpolation was performed by regression kriging as described by [12]. Variables included are total precipitation, minimum and maximum air temperature at daily time step. These data were used to elaborate as an empirical model in order to estimate mildew's pressure in Burgundy, for the 1995 to 2014 period.

For each Burgundy wine sub region, climate data was extracted from several $12 \mathrm{~km}$ grid cells where grapevine is currently grown. These correspond to five, two, ten, four and ten grid cells for "Côte de Beaune", "Côte Chalonnaise”, "Chablisien", "Côte de Nuits" and "Mâconnais” respectively.

\subsubsection{Simulation}

In the case of future climate simulations, CMIP5 climate projections were collected at from ESGF (https://esgfnode.llnl.gov/search/cmip5/). Data from the following eigtheen GCM (General Circulation Models) are used: ACCESS, BCC, CanESM2, CCSM4, CNRM, CSIRO, GFDLM2G, GFDLM2M, INMCM, IPSLCM5A, IPSLCM5B, MIROC, MIROC5, MPILR, MPIMR, MRI, Nor. Here only the RCP8.5 (Representative Concentration Pathways) simulation, corresponding to very high greenhouse gas emissions [13] are used. The simulated climate data time period cover 120 years from 1980 to 2100. Data are statistically downscaled and debiased at a $12 \mathrm{~km}$ grid resolution using the robust quantile mapping method [14]. Note that the quantile mapping is applied at monthly time step.

\subsection{Disease model}

In order to simulate the potential evolution of powdery and downy mildew pressure, we considered the mean number of fungicide sprays per year necessary to control both diseases. Analyzing each disease separately was initially considered. However, the number of powdery mildew and downy mildew treatments performed each year are strongly correlated $(\mathrm{R}=0.98)$. Indeed, in a vast majority of cases, powdery and downy mildew treatments are carried out simultaneously to limit the number of spraying operation in the vineyard. The number of treatments may be the result of high pressure from one disease or another. We therefore considered the sum of treatments number (hereafter referred to as ST, for Sum of Treatments) applied for both diseases each year as a global indicator of grapevine "mildews" pressure. This indicator was compared to monthly climate data on the 1995-2014 period for each Burgundy wine regions. The climate variables used as the model predictors were monthly sum of precipitation (mm) and maximum, minimum and mean temperature, averages from April to July. We tested all the possible models within linear regression, from 65536 combinations. To avoid any multicollinearity within the models, combinations in which at least two predictors were significantly correlated ( $\mathrm{p}$-value $\leq 5 \%$ on a Pearson correlation t-test) were discarded. Each regression model performance was assessed by Leave-One-Out Cross Validation (LOOCV) procedure. The model providing the highest efficiency (EF, see Mayer and Butler 1994 for more information) was selected. EF is calculated as follows:

$$
E F=1-\frac{\sum_{i=1}^{n}\left(P_{i}-O_{i}\right)^{2}}{\sum_{i=1}^{n}\left(O_{i}-\bar{O}\right)^{2}}
$$

where $P_{i}$ is the predicted value of ST in the wine region for year $i$; $O_{i}$ is the observed ST for year $i$ and $\bar{O}$ is the average observed ST for all the $n$ available years. 


\section{Results}

\subsection{Simulated disease pressure}

For the sake on conciseness, only the case of " Côte de Beaune " (CB) wine region is detailed below. Testing all possible combination for simulating ST using April to July monthly precipitation and average temperature resulted in the selection of the following model:

$$
\mathrm{St}_{\mathrm{i}}=-0,213 \mathrm{TX}_{\mathrm{i}} 05-0,382 \mathrm{TX}_{\mathbf{i}} 06+0,026 \mathrm{RR}_{\mathbf{i}} 04+20,713
$$

where, for year $\mathrm{i}, \mathrm{ST}_{\mathrm{i}}$ is the sum of mildews treatments (sprayings) simulated in Côte de Beaune, $\mathrm{TX}_{\mathrm{i}} 05$, $\mathrm{TX}_{\mathrm{i}} 06$ the May and June maximum temperature respectively and $\mathrm{RR}_{\mathrm{i}} 04$ the April precipitation. With this model, ST is simulated with an efficiency equals to 0.61 , a determination coefficient $\left(\mathrm{R}^{2}\right)$ equals to 0.61 and a root mean squared error (RMSE) equals to 1.25 treatment (LOOCV results).

The figure 2 illustrates the relationship between the disease pressure indicator for the selected wine region and the simulated pressure indicator with observed climate data.

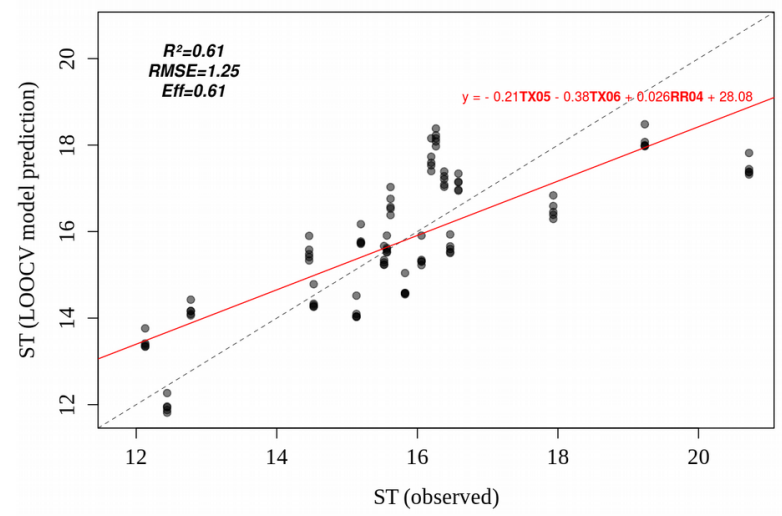

Figure.2 "Côte de Beaune” wine region: mildews spraying number ST observed and simulated through LOOCV.

Selected models and associated LOOCV performances are shown (Table 1). Efficiency ranged from 0.39 to 0.66 . Maximum temperature in May and June as well as April precipitation were selected in the most efficient model of each region.

Table.1 Regressors and LOOCV efficiency (Eff) of multiple linear regression models predicting the sum of treatments for mildews control applied in each major wine region of Burgundy.

\begin{tabular}{l|l|l}
\hline Wine region & \multicolumn{1}{l}{ Regressors (sign) } & Eff \\
\hline Chablisien & -T04 -TN07 + RR05 & 0.39 \\
Côte de Nuits & -TX05 -TX06 +RR04 & 0.40 \\
Côte de Beaune & -TX05 -TX06 +RR04 & 0.61 \\
Côte Chalonnaise & -TN04 -TX05 -TX06 +RR04 +RR06 & 0.66 \\
Mâconnais & -T05 -TX06 +RR04 & 0.47
\end{tabular}

\subsection{Disease pressure projections}

Once each empirical model based on observed climate data (1995-2014) was elaborated for the five sub-wine region of Burgundy, the 18 climate downscaled projections were used to simulate mildews pressure (ST) from 1980 to 2100.

The figure 3 illustrate the evolution of the simulated ST from 1980 to 2100 with the 18 downscaled climate models for the Côte de Beaune wine region (5 grid cells). Each curve represent the trend yearly ST simulated using climate data of one model. The trend is smoothed using the loess method, a non-parametric approach that fits multiple regression in local neighborhood. Simulated ST using projected climate data exhibit a fall for all 18 GCM during the $21^{\text {st }}$ century, with more or less intensity. GCM simulations tend to overestimate ST in the present period (16 to 17.5 treatments per year to control mildews) by comparison to current observations (15.8 treatments in Côte de Beaune, table 2). The spread of simulated ST by all climate models increases throughout the $21^{\text {st }}$ century.

The mean of simulated ST for twenty year was calculated and compared for three periods (1995-2014, 2046-2065, 2081-2100) for each region (Table 1). The delta represents the difference between historical and the futures simulations over the two periods of simulated mildews pressure using all climate models

For each of the 5 wine region, the decrease of mildews pressure was significant (Wilcoxon signed-rank test at alpha $=5 \%$ ) for both the middle and the end of the $21^{\text {st }}$ century periods.

From a geographical point of view, the more the region is located in the South and the stronger the decrease is simulated (Figure 1, Tableau 2). It can be inferred that this trend is mostly due to a projected stronger rise in maximum temperature in the southern regions than it is in the northern regions of Burgundy. For example, in the southern wine region of Mâconnais, the mean maximum temperature projected rise during spring (T04, T05, T06) is $+1,7^{\circ} \mathrm{C}$ and $+1,6^{\circ} \mathrm{C}$ higher than in northern Chablisien region. Futur simulated ST decreased accompanied by increased variability (increase of the standard deviation).

\section{Discussion and conclusion}

This paper assess change in phytosanitary treatments against mildews from 1995 and their evolution in response to climate change throughout the $21^{\text {st }}$ century. To estimate future projection of treatments, we have used an empirical approach using linear/quadratic multiple regression modelling with monthly temperature and precipitation data. Following a robust predictors selection scheme (LOOCV, multicollinearity removal), between 3 and 6 variables are identified as producing the most efficient regression models according wine region. In the case of Côte de Beaune, variables selected are May and June maximum temperature and April cumulated precipitation. These variables are selected in most regions. 
Table.2 Mean sum of treatments on the historical time period (1995-2014) with standard deviation (SD) and mean simulated differences between the historical simulated of ST (Delta) and 2046-2065 and 2081-2100 periods simulated ST for each Burgundy wine region with the $18 \mathrm{GSM}$.

\begin{tabular}{|c|c|c|c|c|c|c|}
\hline \multirow[t]{2}{*}{ Wine regions } & \multicolumn{2}{|c|}{ Observations (1995-2014) } & \multicolumn{2}{|c|}{ Simulations (2046-2065) } & \multicolumn{2}{|c|}{ Simulations (2081-2100) } \\
\hline & Mean & SD & Delta & $\mathrm{SD}$ & Delta & SD \\
\hline Chablisien & 15,1 & 1,2 & $-1,9$ & 1,5 & $-3,8$ & 1,7 \\
\hline Côte de Nuits & 15,7 & 1,6 & $-2,0$ & 2,0 & $-4,0$ & 2,5 \\
\hline Côte de Beaune & 15,8 & 1,6 & $-1,8$ & 1,9 & $-3,6$ & 2,4 \\
\hline Côte Chalonnaise & 14,7 & 2,1 & $-2,3$ & 2,7 & $-4,7$ & 3,2 \\
\hline Mâconnais & 15,0 & 1,9 & $-2,4$ & 2,6 & $-4,9$ & 3,3 \\
\hline
\end{tabular}

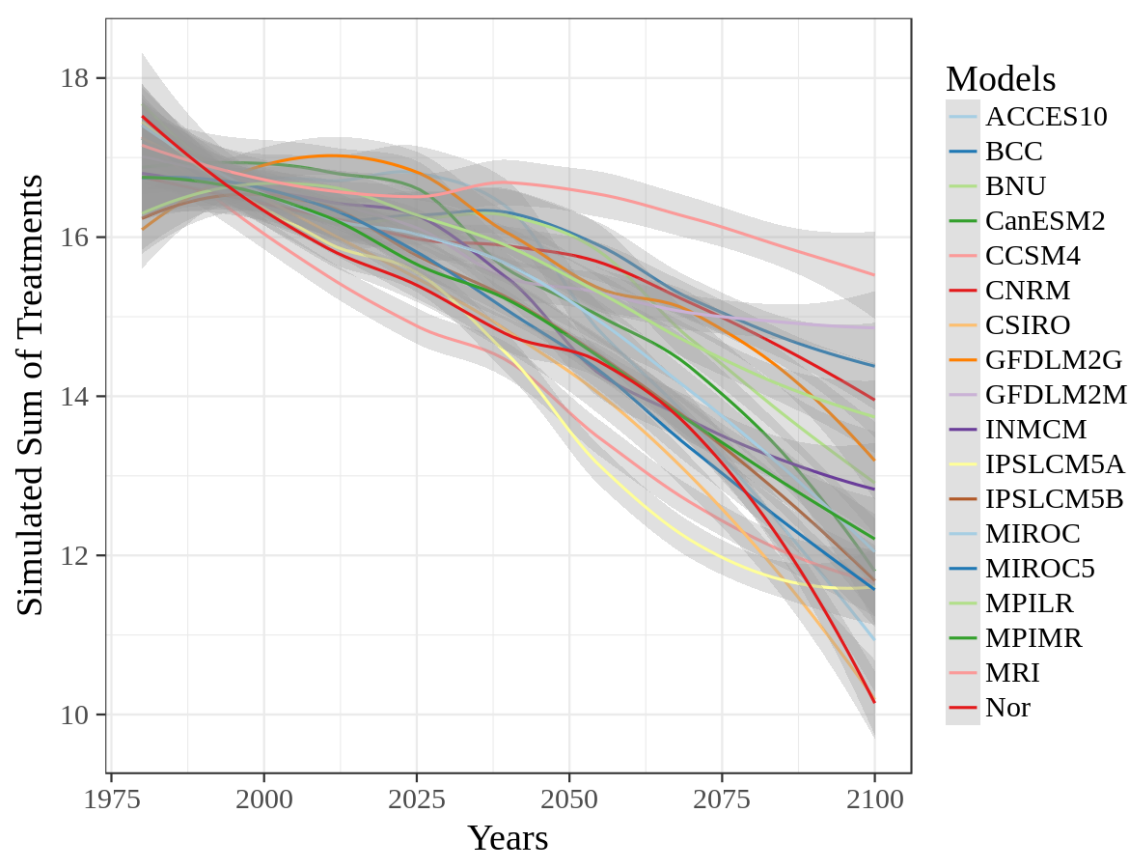

Figure 3. Simulated Sum of treatments with eighteen statistically downscaled GSM data from 1980 to 2100 for the Côte de Beaune wine region.

As primary contamination of both mildews agents (Plasmopara viticola and Erysiphe necator) requires rainfall [15,16], monthly precipitation in April (selected as ST predictors within our model) was logically selected, with a positive regression coefficient. Moreover, rainfall tend to wash out plant protection products on grapevine leaves, which might force the grapegrowers to renew the products application with shorter delays. Temperature regression coefficient are negative, suggesting that increasing air temperature during spring and early summer are detrimental to mildews epidemics outbreaks. These results are contradictory to those of [4] who found that higher temperature during spring enhanced downy mildew pressure. This is rather confusing because one could expect that in cool climate regions such as Burgundy, a raise in temperature would favour secondary cycle length and therefore increase the outbreak speed and severity. An hypothesis is that low temperature may favour higher air humidity and longer leaf wetness duration, and therefore optimum conditions for mildews development. Moreover, for Spring and Summer in France, high monthly temperature are usually correlated with sunny, hence limited number of rainy and humid days.
Because of increasing temperature throughout the $21^{\text {st }}$ century, the regression model simulates globally a fall in pesticide application to control mildews. The spread within models projections increases, indicating that ST is highly sensitive to climate variations provided by both simulated interannual and AOGCM internal variability. Further research is currently being perform to assess the relative contribution to this increase of variability.

According to [17], studying climate change impacts on plant diseases must first take into consideration the potential impacts of global climate on plant population structures and dynamics, micro-evolutionary processes and plant community structures. Physiology, phenology and host/pathogen interactions are equally important factors, as they can influence, positively or negatively, the impact of climate change on diseases [18].

The empirical approach developed here does not allow to address precisely the possible changes in plant/pathogens biology and interactions. Modelling mechanistically both grapevine and mildews agents biology requires high resolution climate data in time (and space) to relevantly simulate plant and pathogens development. Such approach is prevented using monthly climate data, as done in our research. There is a trade of for climate change impact studies between climate data 
robustness and impact models (i.e. plant or pathogen or interaction) relevance. Using poor time resolution (i.e. monthly data) limits the variability and possibly unrealistic simulated climate values through downscaling. But yet the impact modelling is bulk and does not allow to understand the ongoing processes of estimated impacts. Such trade of is little addressed in the scientific literature, while substantial literature discussing the downscaling methods impacts on modelling is available (e.g. $[19,20]$ ), using in most case daily climate data (see for example [21]). This dilemma could be, indeed, to test the robustness and sensitivity of plant-pathogens models to climate variability.

\section{References}

[1] M. Komárek, E. Čadková, V. Chrastný, F. Bordas, J.-C. Bollinger, Contamination of vineyard soils with fungicides: A review of environmental and toxicological aspects, Environment International. 36 138-151 (2010)

[2] Ntzani Evangelia E, Ntritsos G Chondrogiorgi M, Evangelou E, Tzoulaki I, Literature review on epidemiological studies linking exposure to pesticides and health effects, EFSA Supporting Publications. 10 497E (2013)

[3] D. Pimentel, 'Environmental and Economic Costs of the Application of Pesticides Primarily in the United States,' Environment, Development and Sustainability. 7 229-252 (2005)

[4] F. Salinari, G. Simona, T. Francesco Nicola, R. Andrea, R. Vittorio, S. Federico, R. Cynthia, G. Maria Lodovica, Downy mildew (Plasmopara viticola) epidemics on grapevine under climate change, Global Change Biology. 12 1299-1307 (2006)

[5] F. Salinari, S. Giosuè, V. Rossi, F.N. Tubiello, C. Rosenzweig, M.L. Gullino, Downy mildew outbreaks on grapevine under climate change: elaboration and application of an empiricalstatistical model*, EPPO Bulletin. 37 317-326 (2007)

[6] A. Caffarra, M. Rinaldi, E. Eccel, V. Rossi, I. Pertot, Modelling the impact of climate change on the interaction between grapevine and its pests and pathogens: European grapevine moth and powdery mildew, Agriculture, Ecosystems \& Environment. 148 89-101 (2012)

[7] M. Launay, J. Caubel, G. Bourgeois, F. Huard, I. Garcia de Cortazar-Atauri, M.-O. Bancal, N. Brisson, Climatic indicators for crop infection risk: Application to climate change impacts on five major foliar fungal diseases in Northern France, Agriculture, Ecosystems \& Environment. 197 147-158 (2014)

[8] B. Bois, S. Zito, A. Calonnec, Climate vs grapevine pests and diseases worldwide: the first results of a global survey, OENO One. 51133 (2017)
[9] J.M. Murphy, D.M.H. Sexton, D.N. Barnett, G.S. Jones, M.J. Webb, M. Collins, D.A. Stainforth, Quantification of modelling uncertainties in a large ensemble of climate change simulations, Nature. 430 768-772 (2004)

[10] J. Rogelj, M. Meinshausen, R. Knutti, Global warming under old and new scenarios using IPCC climate sensitivity range estimates, Nature Climate Change. 2248 (2012)

[11] K.E. Taylor, R.J. Stouffer, G.A. Meehl, An Overview of CMIP5 and the Experiment Design, Bull. Amer. Meteor. Soc. 93 485-498 (2011)

[12] V. Rossi, T. Caffi, S.E. Legler, Dynamics of Ascospore Maturation and Discharge in Erysiphe necator, the Causal Agent of Grape Powdery Mildew, Phytopathology. 100 1321-1329 (2010)

[13] T. Stocker, ed., Climate change 2013: the physical science basis: Working Group I contribution to the Fifth assessment report of the Intergovernmental Panel on Climate Change, Cambridge University Press, New York, 2014

[14] L. Gudmundsson, J.B. Bremnes, J.E. Haugen, T. Engen-Skaugen, Technical Note: Downscaling RCM precipitation to the station scale using statistical transformations \&ndash; a comparison of methods, Hydrology and Earth System Sciences. 16 3383-3390 (2012)

[15] C. Gessler, I. Pertot, M. Perazzolli, Plasmopara viticola : a review of knowledge on downy mildew of grapevine and effective disease management, Phytopathologia Mediterranea. 50 3-44 (2011)

[16] Gadoury David M., Cadle-Davidson Lance, Wilcox Wayne F., Dry Ian B., Seem Robert C., Milgroom Michael G., Grapevine powdery mildew (Erysiphe necator): a fascinating system for the study of the biology, ecology and epidemiology of an obligate biotroph, Molecular Plant Pathology. 13 1-16 (2012)

[17] S. Chakraborty, A.V. Tiedemann, P.S. Teng, Climate change: potential impact on plant diseases, Environmental Pollution. 108 317-326 (2000)

[18] S.M. Coakley, H. Scherm, S. Chakraborty, Climate Change and Plant Disease Management, Annual Review of Phytopathology. 37 399-426 (1999)

[19] A.W. Wood, L.R. Leung, V. Sridhar, D.P. Lettenmaier, Hydrologic Implications of Dynamical and Statistical Approaches to Downscaling Climate Model Outputs, Climatic Change. 62 189-216 (2004)

[20] C. Teutschbein, J. Seibert, Is bias correction of regional climate model (RCM) simulations possible for non-stationary conditions?, Hydrology and Earth System Sciences. 17 5061-5077 (2013)

[21] J.W. White, G. Hoogenboom, B.A. Kimball, G.W. Wall, Methodologies for simulating impacts of climate change on crop production, Field Crops Research. 124 357-368 (2011) 